\title{
Phylogenetic relationships, stage-specific expression and localisation of a unique family of inactive cysteine proteases in Sarcoptes scabiei
}

Deepani D. Fernando 1,2,3, Simone L. Reynolds ${ }^{1}$, Martha Zakrzewski ${ }^{1}$, Ehtesham Mofiz ${ }^{4,6}$, Anthony T. Papenfuss ${ }^{4,5,6}$, Deborah Holt ${ }^{7}$ and Katja Fischer ${ }^{1 *}$

\begin{abstract}
Background: Scabies is worldwide one of the most common, yet neglected, parasitic skin infections, affecting a wide range of mammals including humans. Limited treatment options and evidence of emerging mite resistance against the currently used drugs drive our research to explore new therapeutic candidates. Previously, we discovered a multicopy family of genes encoding cysteine proteases with their catalytic sites inactivated by mutation (SMIPP-Cs). This protein family is unique in parasitic scabies mites and is absent in related non-burrowing mites. We postulated that the SMIPP-Cs have evolved as an adaptation to the parasitic lifestyle of the scabies mite. To formulate testable hypotheses for their functions and to propose possible strategies for translational research we investigated whether the SMIPP-Cs are common to all scabies mite varieties and where within the mite body as well as when throughout the parasitic life-cycle they are expressed.
\end{abstract}

Results: SMIPP-C sequences from human, pig and dog mites were analysed bioinformatically and the phylogenetic relationships between the SMIPP-C multi-copy gene families of human, pig and dog mites were established. Results suggest that amplification of the SMIPP-C genes occurred in a common ancestor and individual genes evolved independently in the different mite varieties. Recombinant human mite SMIPP-C proteins were produced and used for murine polyclonal antibody production. Immunohistology on skin sections from human patients localised the SMIPP-Cs in the mite gut and in mite faeces within in the epidermal skin burrows. SMIPP-C transcription into mRNA in different life stages was assessed in human and pig mites by reverse transcription followed by droplet digital PCR (ddPCR). High transcription levels of SMIPP-C genes were detected in the adult female life stage in comparison to all other life stages.

Conclusions: The fact that the SMIPP-Cs are unique to three Sarcoptes varieties, present in all burrowing life stages and highly expressed in the digestive system of the infective adult female life stage may highlight an essential role in parasitism. As they are excreted from the gut in scybala they presumably are able to interact or interfere with host proteins present in the epidermis.

Keywords: Sarcoptes scabiei, Scabies, Mites, Skin Infection, Inactive proteases, SMIPP-Cs, Gene expression, Immunohistology, Phylogeny

\footnotetext{
* Correspondence: Katja.Fischer@qimrberghofer.edu.au

${ }^{1}$ QIMR Berghofer Medical Research Institute, Infectious Diseases Program, 300

Herston Road, Herston, Brisbane, QLD 4006, Australia

Full list of author information is available at the end of the article
}

(c) The Author(s). 2018 Open Access This article is distributed under the terms of the Creative Commons Attribution 4.0 International License (http://creativecommons.org/licenses/by/4.0/), which permits unrestricted use, distribution, and reproduction in any medium, provided you give appropriate credit to the original author(s) and the source, provide a link to the Creative Commons license, and indicate if changes were made. The Creative Commons Public Domain Dedication waiver (http://creativecommons.org/publicdomain/zero/1.0/) applies to the data made available in this article, unless otherwise stated. 


\section{Background}

Scabies is a contagious disease caused by the obligatory parasitic burrowing mite Sarcoptes scabiei. This parasite can infect over 100 species of mammals, including humans [1]. The estimated number of human cases every year is between 100-300 million, which is around $2-3 \%$ of the world population [2]. Along with tinea and bacterial skin infections, scabies is one of the most common infectious skin disorders [3]. As scabies is highly contagious and transmitted through contact with infected skin or fomites it is predominantly seen in overcrowded living conditions, typically in economically disadvantaged populations [4]. Young children and the elderly are more commonly affected [5]. Importantly, in tropical climates the initial infection by mites facilitates the invasion of the affected skin with opportunistic, potentially pathogenic bacteria, particularly Streptococcus pyogenes and Staphylococcus aureus. The potential resultant complications include pyoderma, cellulitis, lymphangitis, sepsis, acute post-streptococcal glomerulonephritis, rheumatic fever and rheumatic heart disease [6].

There is no vaccine for scabies, and the few available broad-spectrum anti-parasitic drugs currently used often fail to control the disease $[4,5,7,8]$. For example, the relatively short half-life of ivermectin in the skin [9] dictates repeated consecutive treatments, which causes considerable compliance and management issues. Emerging mite resistance against this leading drug is also of growing concern $[10,11]$. Therefore, new therapeutic options are required. Recent research outputs of scabies mite EST libraries [12], genome [13, 14], proteome [15, 16], transcriptome (manuscript in preparation), established RNAi [17] and re-purposing of FDA approved drugs [9] will accelerate the finding of new therapeutics for this worldwide problem.

Parasite-encoded proteases are essential for regulatory interactions between parasites and their hosts, and thus are considered attractive anti-parasitic drug and/or vaccine targets [18]. Parasitic cysteine proteases are known for their roles in digestion [19], immune evasion [18, 20, 21], enzyme activation in host tissues [22], virulence [23], tissue and cellular invasion [24, 25], excystment [26], and hatching and moulting [24, 27]. Studies emphasised the immune evasion role of parasitic cysteine proteases in evading, suppressing and subverting the host immune responses [28, 29]. Due to their essential roles in the parasitic lifestyles these proteins have been considered as vaccine candidates against many parasites including ectoparasites [30,31], and cysteine protease inhibitors have shown promising results in the control of some parasitic diseases [32, 33].

Scabies mites feed when burrowing within the epidermis [34] and ingest a multitude of diverse host proteins. The feeding success of scabies mites depends on their ability to digest epidermal and plasma components with proteolytic enzymes and to locally modulate the host complement and coagulation systems by releasing pharmacologically active proteins. In the past decade considerable data has been generated indicating that scabies mites express excretory gut proteins involved in these roles [35-37], including one serine protease [38] as well as multiple proteolytically inactive serine protease paralogs (SMIPPSs) [39-41] and serine protease inhibitors (Scabies Mite Serpins, SMSs) [42], both with novel host complementinhibitory functions. There are likely to be multiple specific adaptations within each protein class produced by the mite that are important in the parasite's life-cycle. Exploring these functions may enable us to design specific strategies to interfere with the mite survival.

With this overarching strategy in mind we aimed here to generate fundamental data of a previously discovered unique class of scabies mite cysteine proteases. These are amplified within the scabies mite genome into a multicopy gene family comprised of five proteolytically active and five predicted inactive members featuring mutations in their catalytic sites [43]. The protein products of these genes were termed Scabies Mite Inactivated Cysteine Protease Paralogs (SMIPP-Cs). The closest homologs to the $S$. scabiei cysteine proteases are the group 1 allergens of house dust mite (HDM), which are proteolytic papainlike cysteine proteases that can induce the pathogenic process of asthma and allergy [44-46].

Remarkably, in contrast to the expansion within the scabies mite genome, only a single gene encoding the group 1 cysteine protease allergen has been identified in the close relatives of scabies mites, namely $\operatorname{Der} p 1, \operatorname{Der} f 1$ and Eur $m 1$ in the free living HDM species Dermatophagoides pteronyssinus, D. farinae and Euroglyphus maynei, and Pso o 1 in the non-burrowing sheep scab mite Psoroptes ovis.

The five Scabies Mite Inactive Cysteine Proteases (SMIPP-C a-e), are not only distinct from other parasitic cysteine proteases, they are also distinct from their five active counterparts ( $\operatorname{Sar} s 1$ a-e). In each SMIPP-C the active cysteine has been replaced by a serine. This may or may not lead to inactivation of proteolytic properties of the proteases. In addition, in two of the SMIPP-Cs the active histidine has been replaced by a glutamine (SMIPP$\mathrm{Ca}$ and SMIPP-Cb) and the active histidine of the three other SMIPP-Cs (SMIPP-Cc, SMIPP-Cd and SMIPP-Ce) has been replaced by a leucine. In addition, a glutamine at position 34 of three SMIPP-C sequences (SMIPP-Cc, SMIPP-Cd and SMIPP-Ce) has been replaced by glutamic acid, which has the potential to disturb the formation of the oxyanion hole during hydrolysis [43]. Hence, it has been proposed that these proteases are not able to form a thiolate-imidazolium charge relay diad, and are proteolytically inactive.

Proteolytically inactive proteases, with changes in their catalytic residues or with steric or structural rearrangements 
obscuring the active site and substrate binding pocket, have been shown to accomplish remarkable functions in biological processes including regulation, inhibition and immunomodulation $[47,48]$. The SMIPP-Cs have not been reported in free-living HDMs and were not observed among HDM expressed sequence tags [43]. Consequently, it has been proposed that the presence of the SMIPP-S and SMIPP-C families in burrowing, parasitic scabies mites may be an adaptation to parasitism [39, 43]. Unlike free-living mites, S. scabiei is in direct contact with and must evade host defence mechanisms. If they have essential roles in this context, the SMIPP-Cs may be target proteins for novel immune or chemotherapeutic intervention strategies against scabies.

To elucidate their key functions and to determine if SMIPP-Cs are a potential target to control scabies infection, we have addressed here a range of mandatory key questions regarding their representation and phylogeny across a range of host-specific S. scabiei varieties, their precise location within the mite and in the infected host epidermis and their transcriptional levels in the successive stages of the mite life-cycle.

\section{Methods}

Sequence alignment and phylogenetic analysis of SMIPPCs

Complete amino acid sequences of HDM group 1 allergens; $\operatorname{Der} p$ 1, Der $f 1$ and Eur $m$ 1, S. scabiei var. hominis active cysteine proteases Sar $s 1$ a-e and S. scabiei var. hominis SMIPP-C a-e (accession numbers in Additional file 1: Table S1) were aligned using CLUSTAL O (1.2.0) [49]. Signal sequence and the pro-peptide for individual sequences were predicted using SignalP 4.1 [50] and SMART [51] servers. Glycosylation sites and disulfide bonds were predicted using NetNGlyc 1.0 [52] and the DiANNA 1.1 web server [53], respectively. In silico analyses using MULTALIN [54] and EMBOSS [55] were performed to understand sequence identity among SMIPP-Cs and with the active scabies mite cysteine proteases. SMIPP-C protein sequences from human [12] and dog [14] scabies mites (Additional file 1: Table S1) were used as queries for a local NCBI tBLASTn search to identify homologues of SMIPP-C sequences in the S. scabiei var. suis genome (pig_unwashed and pig washed3) [13] (Additional file 1: Table S1) using an E value threshold of $10^{-5}$. Contig sequences were translated to their amino acid sequences and aligned with protein sequences of Sarcoptes scabiei type hominis Sar $s \quad 1$ allergen (Yv4003H01, Yv9053H09, Yv6030H07) using MAFFT [56]. TrimAl software was applied to remove poorly aligned regions [57]. Prottest v3.4.2 was used to determine the evolutionary model that best fit the data [58], which corresponded to WAG + G + I. A Bayesian phylogenetic tree was calculated using MrBayes software package v3.2.7 with 100,000 generations and sampling every 100 generations [59]. Bayesian posterior probabilities were determined after the initial 'burn-in' period corresponding to $12.5 \%$ of the generations. A maximum likelihood tree was generated using RAML v8.2.11 [60]. Bootstrapping values were calculated based on 100 iterations.

\section{Sequence analysis, cloning, expression and purification of SMIPP-C proteins}

Five genes from the S. scabiei var. hominis SMIPP-C family have previously been identified [43]. Three SMIPPCs from three different clades of the SMIPP-C protein family, SMIPP-Ca (cDNA clone Yv4025A02), SMIPP-Cc (cDNA clone Yv5009F04) and SMIPP-Ce (cDNA clone Yv4028C12) were selected for this study (Additional file 1: Table S1). Predicted mature protein sequences were obtained from NCBI [12] and primers were designed with restriction sites BamHI and NotI for SMIPP-Ca and SalI and PstI for SMIPP-Cc and SMIPP-Ce to achieve directional cloning into the pQE-9 expression vector (Qiagen, Hilden, Germany), in frame with $\mathrm{N}$ terminal $6 \times$ Histidines tags of the expressed proteins. SMIPP-Ca forward primer (5' -acc ggg atc cCA AGA ATT GAC TGA ATC TCC TCC G-3'), SMIPP-Ca reverse primer (5' -acc gct gca gtt aGA ATT CAG GTC GAC CCA ATC TGA C-3'), SMIPP-Cc forward primer (5' -acc ggt cga cTA TTA TTT CGA GAC AAC GCC AAG TGA TGC TG-3') SMIPPCc reverse primer $\left(5^{\prime}\right.$-acc gct gca gtc aTT CAA AAT CTT CAG GCT CAT TTT CAA AAG G-3'), SMIPP-Ce forward primer $\left(5^{\prime}\right.$-acc ggt cga cTA TTA TTT TGA GAC AAC GCC TAG TAT TG-3') and SMIPP-Ce reverse primer (5' -acc gct gca gtc aGG AAT CAT CGG GCT CAG CTT CAA AAG G-3') were synthesised by SigmaAldrich, Australia. Lower case, underlined sections of the primer sequences indicate the incorporated restriction sites. PCR amplified sequences were digested at their restriction sites and ligated into the linearised pQE-9 vector. Ligated vector was transformed into XL1 blue Escherichia coli competent cells and selected on Luria broth (LB)/ampicillin $(100 \mu \mathrm{g} / \mathrm{ml})$ agar. Transformants were confirmed by BigDye 3.1 (Applied Biosystems, Foster City, CA, USA) sequencing using pQE-9 sequence-specific primers.

Sequence confirmed clones were transformed into BL21 E. coli competent cells and proteins were expressed. Briefly a single colony of BL21 $\mathrm{E}$. coli cells was cultured in $\mathrm{LB}$ medium containing $100 \mu \mathrm{g} / \mathrm{ml}$ ampicillin at $37^{\circ} \mathrm{C}$ with $230 \times \mathrm{rpm}$ orbital shaking up to $\mathrm{OD}_{600}$ value $0.5-0.6$. Protein expression was induced by the addition of Isopropyl $\beta$-D-1-thiogalactopyranoside (IPTG) to a final concentration of $1 \mathrm{mM}$ for $4 \mathrm{~h}$. The culture was centrifuged at $6000 \times g$ for $20 \mathrm{~min}$ at $4{ }^{\circ} \mathrm{C}$, and the cell pellet was resuspended in $15 \mathrm{ml}$ of lysis buffer $(50 \mathrm{mM}$ Tris, $10 \mathrm{mM}$ EDTA, $100 \mathrm{mM} \mathrm{NaCl}$, pH 8.0) containing $1 \mathrm{mg} / \mathrm{ml}$ lysozyme, $10 \mu \mathrm{g} / \mathrm{ml}$ DNase, $5 \mu \mathrm{g} / \mathrm{ml}$ RNase, $0.4 \mathrm{ml} / 10 \mathrm{ml}$ cOmplete $^{\mathrm{Tm}}$ EDTA-free protease cocktail (Sigma-Aldrich, 
St. Louis, MO, USA) and $2 \mathrm{mM} \mathrm{MgCl}$, and incubated for $1 \mathrm{~h}$ at room temperature (RT) on a roller. The suspension was homogenised several times using a Potter-Elvehjem homogeniser and sonication of spheroplasts was done by Sonifier 250 (Branson, USA) for 6 times of $30 \mathrm{sec}$ burst cycles with $30 \mathrm{~s}$ cooling intervals in between on ice. The cell lysate was centrifuged at $12,000 \times g$ for $10 \mathrm{~min}$ at $4{ }^{\circ} \mathrm{C}$ and the proteins were detected in the inclusion body cell pellet by Coomassie blue stained 10\% SDS PAGE. Inclusion bodies were washed 6 times with $10 \mathrm{ml}$ of lysis buffer containing $0.5 \%(\mathrm{v} / \mathrm{v})$ Triton-X 100 and recovered by centrifugation $\left(16,000 \times g\right.$, for $20 \mathrm{~min}$ at $\left.4{ }^{\circ} \mathrm{C}\right)$. The washed inclusion bodies were solubilised in $4 \mathrm{ml}$ of $6 \mathrm{M}$ guanidine hydrochloride, $50 \mathrm{mM}$ Tris, $\mathrm{pH} 8.0,100 \mathrm{mM} \mathrm{NaH} \mathrm{PO}_{4}$. $\mathrm{H}_{2} \mathrm{O}$ and $1 \mathrm{mM}$ DTT and bound overnight onto an immobilised and pre-equilibrated Ni-NTA matrix (Qiagen) at 4 ${ }^{\circ} \mathrm{C}$ with circular rotation. Unbound protein flowthrough was collected by gravity flow and the column was washed twice with $5 \mathrm{mM}$ and $10 \mathrm{mM}$ imidazole wash buffers $(6 \mathrm{M}$ urea, $100 \mathrm{mM} \mathrm{NaH} \mathrm{PO}_{4} \cdot \mathrm{H}_{2} \mathrm{O}, 10 \mathrm{mM}$ Tri- $\mathrm{NaOH}, 150$ $\mathrm{mM} \mathrm{NaCl} \mathrm{pH} \mathrm{8.0,1 \%} \mathrm{(v/v)} \mathrm{glycerol} \mathrm{and} 1 \mathrm{mM} \mathrm{DTT})$ to remove non-specifically bound proteins. Target proteins were eluted with $250 \mathrm{mM}$ imidazole in wash buffer at $\mathrm{pH}$ 8.0. The purity was confirmed and proteins were quantified relative to a series of bovine serum albumin (BSA) standards by SDS PAGE analysis with Coomassie blue staining.

\section{Antibody preparation}

Six BALB/c female mice per protein were used for antibody production by immunisation with purified recombinant SMIPP-C proteins. Pre-immune sera were collected from the mice before the protein injections and pooled. Acetoneprecipitated SMIPP-C recombinant proteins were resuspended in 1× PBS buffer and used to immunise the mice. Antibody production was initiated by subcutaneous injection of $50 \mu \mathrm{g}$ recombinant protein emulsified in Freund's Complete adjuvant (Sigma-Aldrich, USA) and boosted twice with 2 weeks interval with the same amount of protein doses emulsified with Freund's Incomplete adjuvant (Sigma-Aldrich, USA). After the third immunisation, antibody production and specificity were tested using Odyssey ${ }^{\circ}$ western blot. Odyssey western blot in brief: SMIPP-C proteins were loaded separately on 10\% SDS PAGE and transferred to an Immubolin-FL PVDF membrane (Merck Millipore, Temecula, CA, USA). All following incubation steps were done at RT for $1 \mathrm{~h}$ with gentle orbital shaking unless stated otherwise. The membrane was blocked with Odyssey blocking buffer (LI-COR Biosciences, Lincoln, NE, USA) followed by incubation with 1:500 diluted mouse sera and washed 3 times with PBS-0.05\% TWEEN $^{\circ} 20$ (PBST). Bound antibodies were detected by incubation with goat anti-mouse-IR $800 \mathrm{~nm}$ secondary antibodies (LI-COR Biosciences) 1:10,000 and the membranes were washed 3 times as before. Antibody binding was visualised by the Odyssey Infrared Imaging System (LI-COR Biosciences, USA) and images were analysed using the Image Studio ${ }^{\mathrm{Tm}}$ Lite 5.2.5 software. Mouse serum was harvested upon positive results. Antibody cross reactivity was tested between each SMIPP-C protein and against active cysteine protease Sar $s$ using Odyssey ${ }^{\circ}$ western blot as described above.

\section{Immuno-histological localisation}

The localisation of SMIPP-C proteins within and in the vicinity of the scabies mite was demonstrated using sections of human skin infested with mites probed with the polyclonal antibodies raised in mice against individual SMIPP-Cs. Adjacent serial sections were probed with anti-human IgG, which is known to be ingested by the mite [61] and therefore serves as a marker to localise gut tissue. Adjacent serial sections were also probed with preimmune mouse serum as a negative control. Paraffin blocks of $5 \mathrm{~mm}^{3}$ scabies-infected human skin tissues [62] were used to cut $4 \mu \mathrm{m}$ sections and coated on $\mathrm{X}-\mathrm{Tra}^{\mathrm{Tx}}$ (Leica Biosystems, Nußloch, Germany) glass slides. The slides were dried at $37^{\circ} \mathrm{C}$ for $3 \mathrm{~h}$ and dewaxed in xylene followed by graded ethanol. All the incubation steps were done at RT in a humidifier chamber and all the washes were 3 times of 5 min with Tris Buffered Saline (TBS pH 7.6) unless stated otherwise. Endogenous peroxidase activity was blocked with $3 \% \mathrm{H}_{2} \mathrm{O}_{2}$ in TBS for $10 \mathrm{~min}$ and the slides were washed. Non-specific protein binding was blocked with $10 \%$ goat serum in TBS for $30 \mathrm{~min}$. Excess serum was decanted and the slides were probed with preimmune mouse sera (negative control) or with SMIPP-C specific antibody (test) overnight at $4{ }^{\circ} \mathrm{C}$. Test and negative control slides were washed and probed with antimouse probe MACH1 (Biocare Medical, Pacheco, CA, USA) secondary antibody for $20 \mathrm{~min}$ at RT. Both slides were first washed with TBST followed by 2 washes with TBS and probed with MACH1 universal HRP polymer (Biocare Medical) for 20 min followed by 3 TBST washes. A third serial tissue section (positive control), blocked for endogenous peroxidase activity and nonspecific binding, was probed with horseradish peroxidase (HRP) labelled anti-human IgG (Sigma-Aldrich, USA) for $1 \mathrm{~h}$ at RT as a mite gut marker [61]. It was followed by a wash with TBST and 2 subsequent washes with TBS. Nova-RED substrate (VECTOR LABORATORIES, Burlingame, CA, USA) was added to all three sections to initiate the chromogenic reaction and it was stopped by immersion in deionised water for $3 \mathrm{~min}$ at RT. The slides were counterstained with haematoxylin for $1 \mathrm{~min}$, dehydrated in graded ethanol, cleared in xylene and mounted with DPX histology slide mounting medium (Sigma-Aldrich, USA). Slides were visualised using an Aperio XT Scanscope (Leica Biosystems) slide scanner at 40× magnification and 
analysed using eSlide manager and ImageScope viewing softwares (Leica Biosystems).

\section{Identification of S. scabiei var. hominis life stages}

Between 20-100 individual organisms representing the different life stages of S. scabiei var. hominis preserved in TRIzol (Invitrogen, Carlsbad, CA, USA) were separated first under a stereo binocular dissecting microscope and subsequently males and nymphs were further separated under a bright field microscope at $40 \times$ magnification. Eggs are glossy, whitish and ovoid with enclosed embryo or larvae in its foetal stage. Larvae have only 3 pairs of legs and are similar in size to the eggs. Females are the largest and have an ovoid creamy-white coloured body with 4 pairs of legs; 2 pairs of anterior legs end with small suckers and the hind 2 pairs end with long seta. Males are approximately two thirds the size of a female and similar in size to nymphs. Males and nymphs have 4 pairs of legs; however, a distinctive difference under the bright field microscope (at 40x magnification) is that both pair of hind legs end with long seta in nymphs, but in males the inner pair of hind legs terminates as a broad pad [63].

\section{Amplification of SMIPP-C transcripts by ddPCR}

SMIPP-Ca, SMIPP-Cc and SMIPP-Ce primers were designed to amplify relatively conserved regions containing $123 \mathrm{bp}, 151 \mathrm{bp}$ and $98 \mathrm{bp}$, respectively for droplet digital PCR (ddPCR). Primer sequences are, SMIPP-Ca forward primer (5'-GCG AGG AAA ATG TCA AGA GA-3'), SMIPP-Ca reverse primer ( $5^{\prime}$-GGG CAC CGT ATG CGG ACA AAT-3'), SMIPP-Cc forward primer (5'-CAG ACA GGC GCG ATT AGA AC-3'), SMIPP-Cc reverse primer (5'-CCA CGA TGC TTT ACA TTT ACT TTC GGT TG-3'), SMIPP-Ce forward primer (5'-CCG AGA TTA TTG GGT CGT TAA G-3'), SMIPP-Ce reverse primer (5'-CCA AGA TAC CGA AAA GAT TCT CTT CC-3'). The primers were used to amplify the SMIPP-C fragments from S. scabiei var. hominis cDNA libraries [12] by conventional PCR with cycling conditions; $95{ }^{\circ} \mathrm{C}$ for $10 \mathrm{~min}$, 35 cycles of $95{ }^{\circ} \mathrm{C}$ for $30 \mathrm{~s}, 54{ }^{\circ} \mathrm{C}$ for $30 \mathrm{~s}$ and $72{ }^{\circ} \mathrm{C}$ for 1 min, and final extension at $72{ }^{\circ} \mathrm{C}$ for $7 \mathrm{~min}$. DNA negative and primer negative controls were also included. Resulting products were cloned into the pUC19 vector using a PCR cloning kit (NEB, Ipswich, MA, USA) according to the manufacturer's instructions. The primer specificity was confirmed by BigDye 3.1 sequencing (Applied Biosystems).

The sensitivity of the primer pairs was evaluated by testing different primer concentrations from $50 \mathrm{nM}$ to 200 $\mathrm{nM}$ final concentrations; $100 \mathrm{nM}$ final was the optimal concentration for all three sets of ddPCR primers in the reaction mix. Temperature gradient ddPCR conditions established the optimised annealing temperatures for the SMIPP-Ca, SMIPP-Cc and SMIPP-Ce ddPCR primers as $63^{\circ} \mathrm{C}, 60^{\circ} \mathrm{C}$ and $56^{\circ} \mathrm{C}$, respectively.
To investigate whether SMIPP-C transcription is stagespecific, different life stages of $S$. scabiei var. hominis mites preserved in TRIzol were separated, using previously established methods [63] under stereoscopic and bright field microscopes. S. scabiei var. hominis eggs, larvae, nymphs, males and females were collected separately into Direct-zol $^{\text {Tm }}$ (Zymo Research, Irvine, CA, USA) and the Direct-zol $^{\text {Tw }}$ RNA MicroPrep kit (Zymo Research) was used to extract mite total RNA according to the manufacturer's instructions. cDNA was synthesised using Superscript $^{\circ}$ II reverse transcriptase (Thermo Fisher Scientific) and Oligo $(\mathrm{dT})_{20}$ primer (Thermo Fisher Scientific). Prepared cDNA was used to amplify SMIPP-C transcripts by ddPCR using specific primers. Reactions were performed in $20 \mu \mathrm{l}$ reactions, consisting of $1 \times$ EvaGreen supermix (Bio-Rad, Hercules, CA, USA), $100 \mathrm{nM}$ forward primer, $100 \mathrm{nM}$ reverse primer, $1 \mu \mathrm{l} \mathrm{cDNA}$ and molecular grade water (Invitrogen) in a semi-skirted twin.tec 96 well PCR plate (Eppendorf AG, Hamburg, Germany). ddPCR cycling times were $95{ }^{\circ} \mathrm{C}$ for $10 \mathrm{~min}$ followed by 45 cycles of $95{ }^{\circ} \mathrm{C}$ for $30 \mathrm{~s}$, annealing temperature for $30 \mathrm{~s}$ and $72{ }^{\circ} \mathrm{C}$ for $1 \mathrm{~min}$, and final extension at $72{ }^{\circ} \mathrm{C}$ for $10 \mathrm{~min}$ followed by a single final dye stabilization step of $4{ }^{\circ} \mathrm{C}$ for $5 \mathrm{~min}$ and $95{ }^{\circ} \mathrm{C}$ for $5 \mathrm{~min}$. SMIPP-C gene transcription was quantified using a QX200 droplet digital PCR system (Bio-Rad) and analysed using the appropriate automated QuantaSoft software (Bio-Rad). Target gene transcription was calculated as SMIPP-C gene transcript copy numbers per individual mite or egg. All error bars were generated by QuantaSoft software and represent a $95 \%$ confidence interval.

\section{Results}

Sequence alignment of the S. scabiei var. hominis SMIPP-C family

Homologous features and differences between the group $1 \mathrm{HDM}$ allergens the active SM cysteine proteases Sar $s$ 1 a-e and the SMIPP-Cs are shown in the CLUSTAL O alignment of the protein sequences in Fig. 1. Eight out of ten scabies mite proteins have a confirmed signal sequence, indicating their secretory nature, as is seen with the HDM group 1 allergens. All SMIPP-Cs however lack a predicted pro-peptide and have further distinct features. While they share regions of homologous sequence with the active protease sequences (highlighted in pink in Fig. 1), they display unique conserved regions which could potentially result in different structural and functional properties (Fig. 1, green highlighting). The mutated catalytic sites and mutations in the glutamine, which is important for oxyanion hole formation, are indicated in blue and yellow, respectively [43]. All five SMIPP-Cs have four predicted disulfide bonds (Fig. 1, pentagons) compared to between 3 and 7 disulfide bonds predicted in the proteolytically active counterparts 


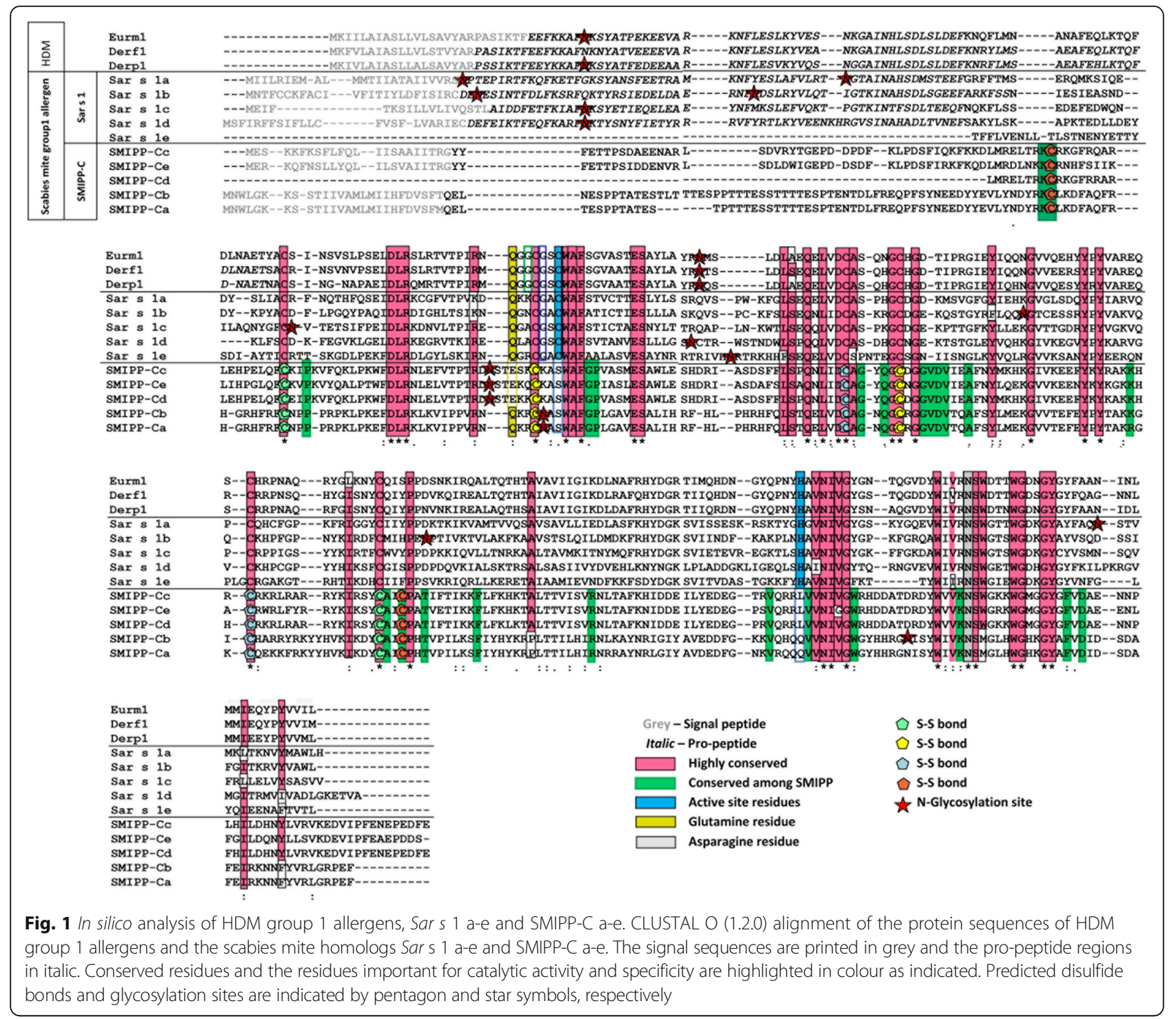

of HDMs and scabies mites (not shown). The pattern of predicted glycosylation is distinctively shifted in the SMIPP-Cs (Fig. 1, red stars). All of these differences between the SMIPP-Cs and their active equivalents may be noteworthy, as the distinct changes in pro-peptides, catalytic sites, disulfide bonds and glycosylation previously reported for the SMIPP-Ss [41] are thought to have led to structural changes and ultimately to an altered function [54, 55]. Sarcoptes scabiei var. hominis SMIPP-Cs have 22-26\% protein sequence identity with the HDM group 1 allergen (Der $p 1$ ) and 21.5-27\% protein sequence identity with the scabies mite active cysteine proteases ( $\operatorname{Sar} s 1$ a-e). The five members of SMIPP-C family have between $31-93 \%$ amino acid identity to each other. SMIPP-Ca and SMIPP-Cb as well as SMIPP-Cd and SMIPP-Ce show a very high protein identity of $93 \%$ and $81.5 \%$, respectively.

\section{Phylogenetic analysis of human, pig and dog mite SMIPP-Cs}

Five additional SMIPP-C sequences identified in the recently established S. scabiei draft genome databases of dog [14] and pig [13] mites were converted into amino acid sequences and were included in the phylogenetic analysis implemented using a Bayesian inference to complement previous phylogenetic tree analyses of SMIPP-Cs in human and dog mites [16, 43]. Phylogenetic comparison of SMIPP-Cs of S. scabiei var. hominis (human mite), $S$. scabiei var. suis (pig mite) and S. scabiei var. canis (dog mite) indicated that amplification of the SMIPP-C genes into a family of five occurred in a common ancestor and individual genes evolved independently in the different mite varieties (Fig. 2). Notably, the SMIPP-Cf lineage only occurred in pig and dog mites but not in human mites. The SMIPP-Cd is another variant of SMIPP-Cc and only 


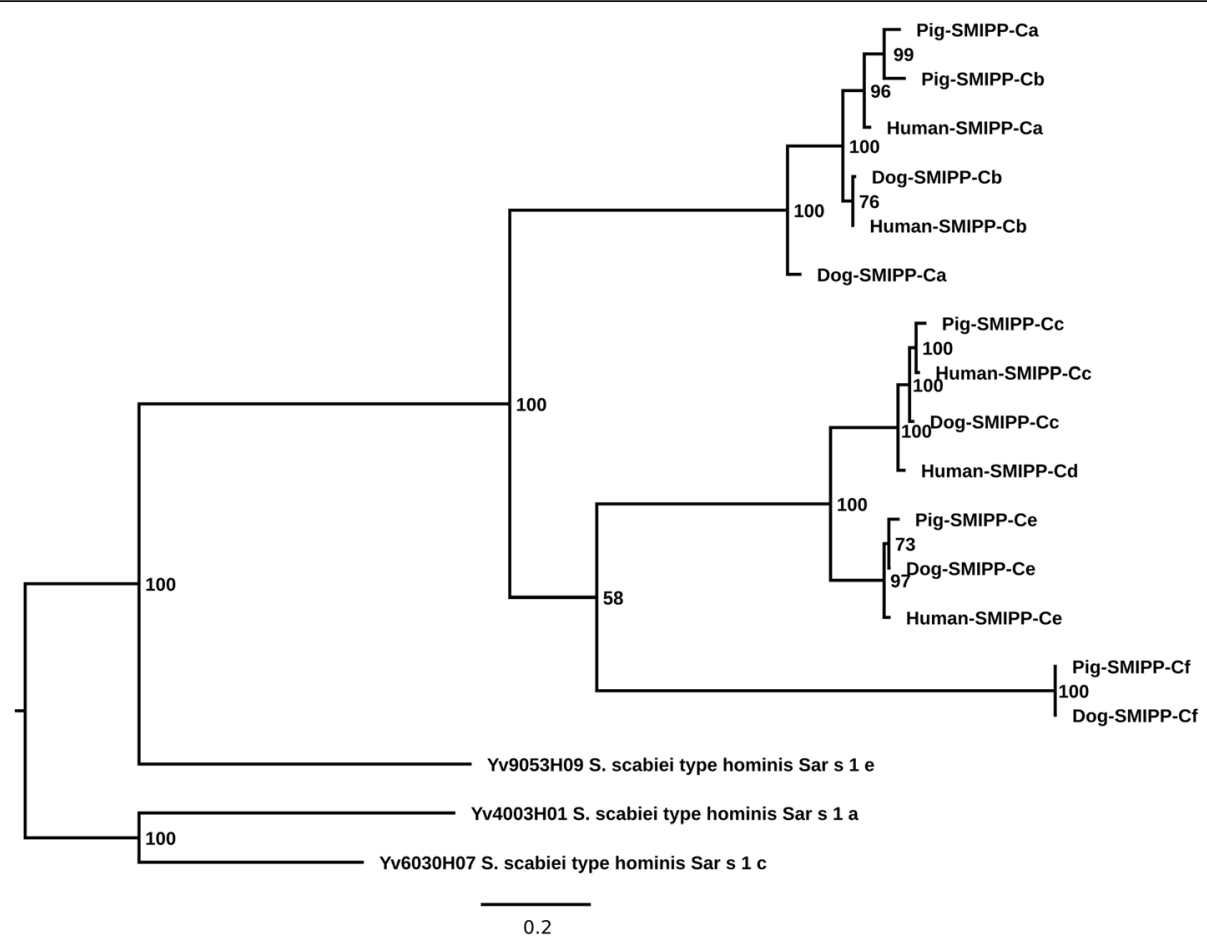

Fig. 2 Phylogenetic relationships of SMIPP-Cs. The phylogenetic relationship between amino acid sequences of S. scabiei var. hominis (Human-SMIPP-C), S. scabiei var. suis (Pig-SMIPP-C) and S. scabiei var. canis (Dog-SMIPP-C) was estimated by Bayesian inference (accession numbers are provided in Additional file 1: Table S1). Numbers at nodes represent Bayesian posterior probabilities. The tree was rooted using Sarcoptes scabiei type hominis Sar s 1 allergen protein sequences (Yv4003H01, Yv9053H09, Yv6030H07)

occurred in human mites. The dog SMIPP-Ca is remarkably different compared to all other SMIPP-C variants. The results were confirmed in a phylogenetic analysis using a maximum likelihood approach implemented in RAxML (Additional file 2: Figure S1).

\section{Cloning, expression and purification of SMIPP-C proteins} Sarcoptes scabiei var. hominis SMIPP-Cs from three different clades (SMIPP-Ca, SMIPP-Cc and SMIPP-Ce) were produced as His-tagged recombinant proteins. Fragments equivalent to the predicted mature amino acid sequences were amplified by PCR from existing expressed sequence tag (EST) libraries. Sequencing confirmed that SMIPP-Ca, SMIPP-Cc and SMIPP-Ce clones were $100 \%$ identical to the published GenBank sequences [12]. Mature sequence predicted molecular weights and isoelectric points including the $\mathrm{C}$ terminal His-tag were predicted to be $36.16 \mathrm{kDa}$ and $\mathrm{pI} 9.24$ for SMIPP-Ca, $37.24 \mathrm{kDa}$ and pI 8.74 for SMIPP-Cc and 39. $14 \mathrm{kDa}$ and $\mathrm{pI} 6.13$ for SMIPP-Ce. The proteins were expressed in BL21 E. coli cells, isolated from inclusion bodies under denaturing conditions and purified via affinity chromatography. Purified proteins from all 3 SMIPP-Cs were of high purity, as shown in a Coomassie blue stained gel analysis (Fig. 3a).
We immunised mice with purified recombinant SMIPP$\mathrm{C}$ proteins and tested the antibody specificity by Odyssey ${ }^{\circ}$ western blot. The polyclonal antibodies raised against SMIPP-Ca were highly specific and did not cross react with any other SMIPP-Cs tested (Fig. 3b; Lanes 2-4). The antibodies raised against SMIPP-Cc and SMIPP-Ce cross reacted with both SMIPP-Cc and SMIPP-Ce proteins (Fig. 3c, d; Lanes 3 and 4), but not with SMIPP-Ca (Fig. 3c, d; Lanes 2). Notably, none of the SMIPP-C antibodies cross reacted with their proteolytically active counterpart, the scabies mite active cysteine protease Sar s 1c (Fig. 3b, c, d; Lanes 5). A western analysis probing scabies mite extracts with the individual sera showed single bands of similar size for the three sera, indicating reactivity to the native proteins in the extract (Additional file 3: Figure S2). It was concluded that the antibodies raised against recombinant proteins of S. scabiei var. hominis SMIPPCs were suitable reagents for immunolocalisation of SMIPP-Cs expressed by scabies mites.

\section{Immuno-histological localisation of SMIPP-Cs}

The localisation of SMIPP-C proteins within and in the vicinity of scabies mites in human skin was demonstrated using the polyclonal antibodies raised in mice against individual SMIPP-C proteins [61]. All three 


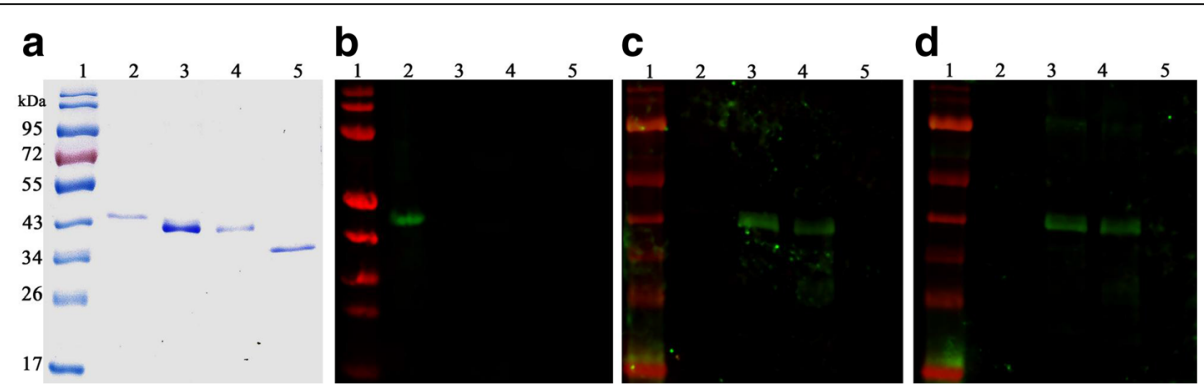

Fig. 3 Specificity of mouse sera against recombinantly expressed and affinity purified SMIPP-Ca, SMIPP-Cc and SMIPP-Ce. Coomassie blue R-250 stained SDS PAGE (a) and western blots using antibodies against SMIPP-Ca (b), SMIPP-Cc (c) and SMIPP-Ce (d) recombinant proteins. Lane 1: protein marker; Lane 2: SMIPP-Ca; Lane 3: SMIPP-CC; Lane 4: SMIPP-Ce; Lane 5: Sar s 1c recombinant proteins. Predicted molecular weights of SMIPP-Ca, SMIPP-Cc, SMIPP-Ce and Sar s 1c are 36.16 kDa, 37.24 kDa, $36.46 \mathrm{kDa}$ and $34.73 \mathrm{kDa}$, respectively

SMIPP-Cs investigated were localised to the digestive system of the mite (Fig. 4c). Sections probed with antibodies against SMIPP-Ca, SMIPP-Cc and SMIPP-Ce stained positive (red staining: Fig. 4, sections $1 \mathrm{c}, 2 \mathrm{c}$ and $3 c$, respectively) in regions that were identified as mite gut tissue with the gut-specific anti human IgG antibody (Fig. 4: sections 1a, 2a and 3a, respectively) and in mite faeces (Fig. 4e). Given the cross-reactivity of antibodies against SMIPP-Cc and SMIPP-Ce, immuno-histology using these probes may show localisation of SMIPP-CC and/or SMIPP-Ce to the mite digestive system and mite faeces. All sections probed with pre-immune mouse sera (negative control) showed the counter stain and the unstained pale to dark brown colour of chitin and faeces (Fig. 4: sections $1 \mathrm{~b}$ and $\mathrm{d}, 2 \mathrm{~b}$ and $\mathrm{d}$, and $3 \mathrm{~b}$ and $\mathrm{d}$ ).
Amplification of SMIPP-C transcripts by ddPCR to evaluate the stage-specific SMIPP-C expression at the transcriptional level

Initial primer testing and optimization of the PCR assays for the amplification of the selected three SMIPP-C sequences was done by conventional PCR using DNA extracted from pUC19 clones of SMIPP-Ca, SMIPP-Cc and SMIPP-Ce. No cross-amplification was observed, indicating that the SMIPP-C ddPCR primers were sequence-specific [63]. Between 20 and 100 single organisms representing each life stage (eggs, larvae, nymphs, adult males and adult females) were pooled. Stage-specific cDNA preparations were subjected to the established ddPCR assay. Using this methodology, we were able to quantify stage-specific SMIPP-C gene transcription and to

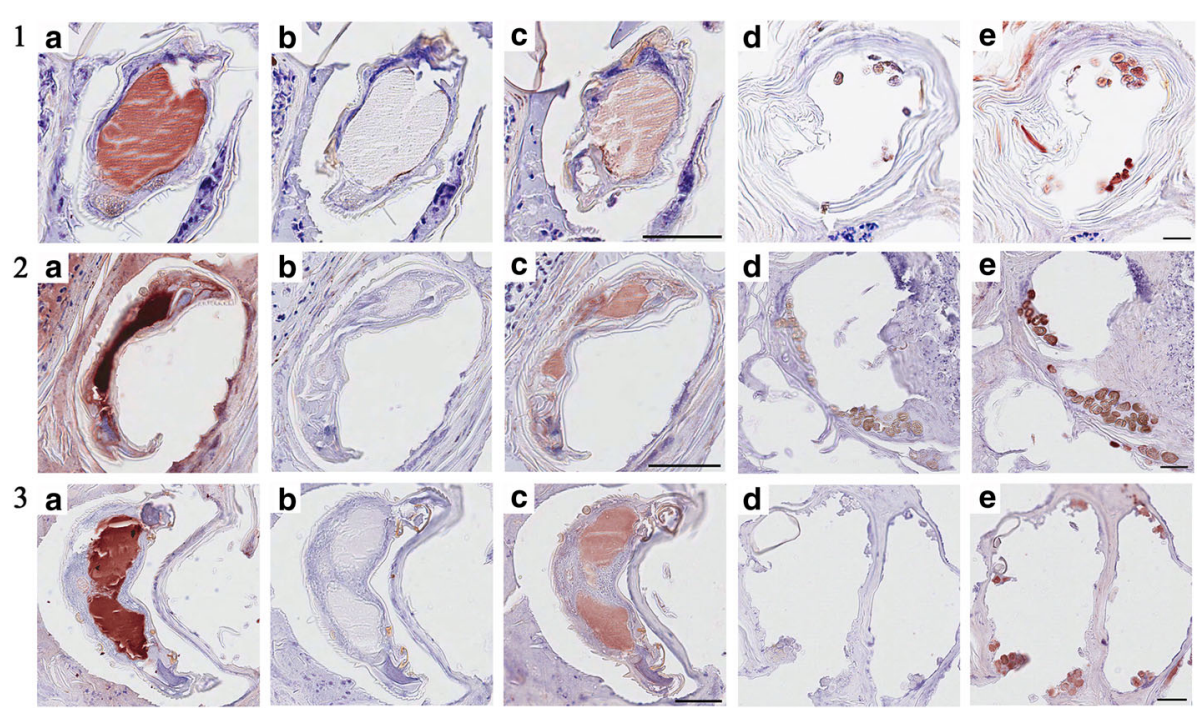

Fig. 4 Localisation of SMIPP-CS in S. scabiei var. hominis infected epidermal tissue by immuno-histochemistry. Series 1, 2 and 3 are serial histological sections of scabies mite infested human skin showing localised SMIPP-Ca, SMIPP-Cc and SMIPP-Ce proteins. a-c S. scabiei var. hominis mites within human skin burrows. $\mathbf{d}$, e Mite faecal pellets. a Probed with anti-human IgG (mite gut marker). b, d Probed with pre-immune mouse sera (negative control). c, e Probed with SMIPP-C specific antibodies. Red staining indicates antibody binding to protein. Scale-bars: $50 \mu \mathrm{m}$ 
calculate the gene transcript copy numbers per individual life stage. Compared to all other life stages, SMIPP-Ca, SMIPP-Cc and SMIPP-Ce were highly expressed in adult females (between 43 and 170 times higher), accounting for $15,259.3 \pm 493.8,17,530.9 \pm 395.1$ and $4508.6 \pm 222.2$ gene transcript copies per single female mite, respectively (Fig. 5).

\section{Discussion}

The enzymatically inactive SMIPP-Cs described here are unique to parasitic scabies mites and have not been reported to be present in the closely related free living HDMs. We postulated previously that the evolution of SMIPP-Cs may be an adaptation to the parasitic state [39]. Since then SMIPP-Cs have not been observed among HDM ESTs [39] or in the more recent HDM genome database [64]. The proposed essentiality of the SMIPP-Cs for the parasitic scabies mite is further emphasised by their demonstrated presence in three $S$. scabiei varieties of medical and veterinary importance. The SMIPP-C proteins are homologous to the five scabies mite active cysteine proteases ( $\operatorname{Sar} s 1 \mathrm{a}$-e) and to the group one allergen of HDMs [43]. Figure 1 illustrates that the SMIPP-C amino acid sequences are conserved among each other and distinctly different to the active cysteine proteases. Their unique sequence features are likely have distinct structural and functional properties. Our phylogentic analysis aligns with previous studies $[15,43]$, indicating that they are a monophyletic gene family. We propose that the SMIPP-Cs were amplified in the most common recent ancestor of the three mite varieties, and that the sequence variation between the mite varieties is consistent with sequence variation

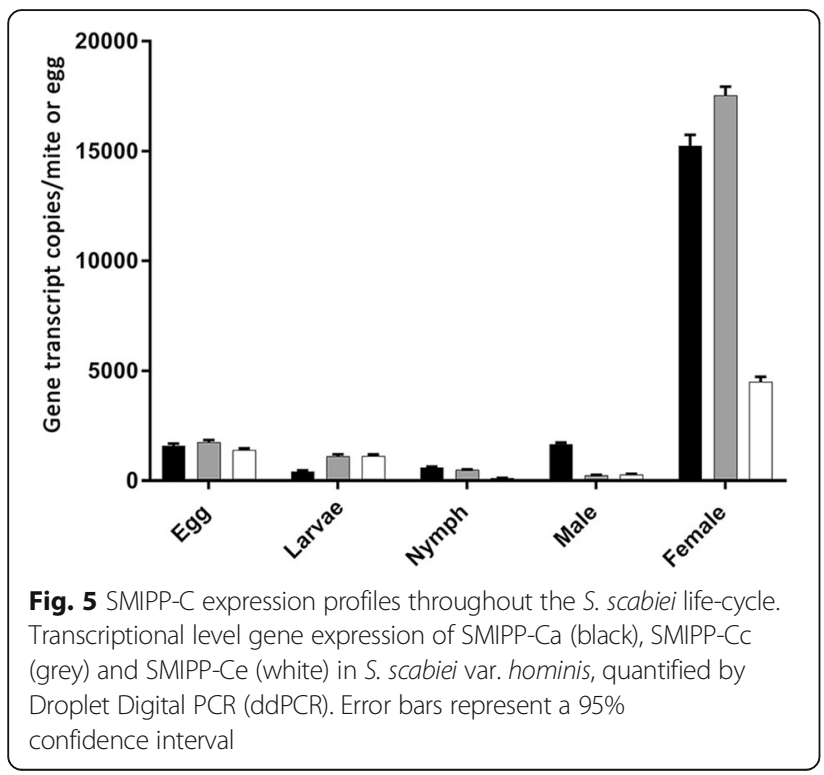

between the mite varieties at other loci. Within each scabies mite variety the SMIPP-Cs evolved into slightly different variants, presumably as the sub-speciation along with the adaptation to different hosts occurred. While the SMIPP-Cf lineage only occurred in pig and dog mites but not in human mites it seems that the human mites have two different versions of SMIPP-Cc and no SMIPP-Cf. The data indicate that the amplification happened prior to host species adaptation and that the sequence variation happened with host adaptation. We hypothesize that, provided the SMIPP-C proteins have an essential function for the parasite, these seemingly inconsequential differences in SMIPP-C evolution could contribute to the strict host specificity seen in scabies mites.

The fact that SMIPP-Cs are expressed and have been amplified into multicopy families indicates that despite their proteolytic inactivity, the SMIPP-C genes are not redundant pseudogenes. Despite their catalytic mutations and the expected lack of proteolytic activity in the encoded proteins, they may have evolved new functions and may interact with host proteins in different, nonproteolytic ways. A recent review summarised the extensive and expanding role of pseudoproteases in other regulatory functions and immune evasion using alternative binding sites or exosites [48]. For example, the proteolytically inactive kinase ROP5 of Toxoplasma gondii has been found to contribute to virulence and host immune evasion [65]. Also, the metacapase 4 (MCA4) of Trypanosoma brucei plays a role in blood stage parasite cytokinesis and virulence despite having its active site histidine altered to serine, resulting in no proteolytic activity [66].

Our finding that SMIPP-Cs are transcribed and expressed in all burrowing stages may indicate an important role of these proteins in the parasitic life style. The highest expression of SMIPP-Cs were seen in female mites (Fig. 5). Female scabies mites play a major role in transmission and establishment of the disease [4]. Similarly, only the two spotted spider mite (Tetranychus urticae) females emigrate and colonize, and the highest levels of digestive proteins are expressed mainly in adult stages [67]. To confirm and to determine the location of expression within the mite body we generated antibodies against representative SMIPP-Cs from three different clades within the human mite SMIPP-C protein family. Notably, the grouping of the SMIPP-Ca protein into a different clade from SMIPP-Cc and SMIPP-Ce (Fig. 2) may explain the observed lack of cross reactivity of antibodies against SMIPP-Ca to the other SMIPP-Cs (Fig. 3). Even so, all three antibodies stained solely and consistently the intestinal tract and the faeces (Fig. 4), identifying the SMIPP-Cs as secreted intestinal and excretory proteins. 
Similarly, the HDM [68] and the Psoroptes mite [69] group one allergens have been localised in the mite digestive system and in its excretions. These potent allergens present in the mite faeces have been hypothesised to interfere with the host inflammatory response in affected tissues to trigger allergic responses [70]. The active scabies mite cysteine proteases Sar $s$ a-e likely have similar digestive functions, and interestingly there is also expansion of this family compared to the counterparts in free-living mites.

The mite intestinal tract and its content are certainly an important yet vulnerable compartment of the scabies parasite. While the rest of the organism is physically protected against host defence mechanisms by an impermeable chitin armour, this organ makes available a very large interface with the physiology of the host epidermis, to allow nutrient uptake and excretion. Digestion and nutrient uptake must occur through the gut lining while its damage through host defence mechanisms must be prevented. Many parasitic arthropods have evolved multiple ways to overcome this problem (reviewed in [71]). The scabies mite produces 33 gut proteins that are closely related to the HDM group 3 allergen. One of them, the serine protease Sar s 3, cleaves human filaggrin, thereby contributing to the breakdown of the epidermal barrier as the mite burrows within the epidermis [38]. The remaining 32 serine protease-like molecules (SMIPP-Ss [41]) contain mutations in the conserved active-site catalytic triad that are predicted to render them catalytically inactive. Some SMIPP-Ss have been shown to inhibit complement activation $[40,72]$ by interfering with the lectin pathway of complement activation [73], thereby protecting the mite gut lining from complement-mediated damage and enabling the mite to evade the host immune system. Two SMIPP-S crystal structures were generated [41] to elucidate the evolution of this functional change. Another class of mite proteins, namely the scabies mite SMSs, are also localised in the mite gut and in faecal pellets and also intefere with the complement cascade [42]. The accumulation of multiple mite complement inhibitors in the confined space of the mite burrow is thought to promote the survival of scabies associated pathogenic bacteria [72, 74, 75]. The fact that SMIPP-Cs are gut localised and released into the epidermis may be indicative of a role in host-parasite interaction. As shown for the SMIPP-Ss, the SMIPP-Cs may interfere with host proteins that are ingested or present in the immediate vicinity of the mite. The similarities in the evolution of these unique families emphasizes this possibility. Although the interactions of SMIPP-Cs with host mechanisms remain to be elucidated, we have delivered here the groundwork for future functional characterisation by providing evidence of when, where and in what relative quantities they are expressed throughout the parasite life-cycle.

\section{Conclusion}

The family of the SMIPP-Cs is translated and expressed, consequently the genes with mutated catalytic diads are not redundent genes in the mite genome. Their amplification into a multicopy family and their presence within three varieties of scabies mites and expression in the mite intestinal system indicate a definite role of these proteins. Their availability to interact with host epidermal tissue and host defence systems may highlight an essential role in parasitism.

\section{Additional files}

Additional file 1: Table S1. Protein and scaffold accession numbers of S. scabiei SMIPP-Cs and homologous HDM and scabies mite cysteine proteases. (DOCX $16 \mathrm{~kb}$ )

Additional file 2: Figure S1. Phylogenetic tree inferred from a Maximum Likelihood approach implemented in RAxML. Numbers at nodes represent bootstrap values based on 100 iterations. The tree was rooted using Sarcoptes scabiei var hominis Sar $s 1$ allergen protein sequences (Yv4003H01, Yv9053H09, Yv6030H07). (DOCX 87 kb)

Additional file 3: Figure S2. Western analysis of whole mite extract. Lane 1: Coomaasie blue stain. Western blots using sera raised against SMIPP-Ca (Lane 2), SMIPP-Cc (Lane 3) and SMIPP-Ce (Lane 4). (DOCX 197 kb)

\section{Acknowledgements}

We wish to acknowledge the late Professor Dave J. Kemp, who championed the work on molecular aspects of scabies, a neglected disease particularly of the poor. We acknowledge Ms. Mei-Fong Ho for antibody production of two SMIPP-C proteins. We acknowledge Mr. T Nguyen for assistance in imaging at ACRF Centre for Comprehensive Biomedical Imaging and Mr. G Rees assistance in the Histology Laboratory at the QIMR Berghofer Medical Research Institute.

\section{Funding}

This research was supported by funding from the Australian Government National Health and Medical Research Council (Project Grant ID 1067192). KF was supported by an Australian Research Council Future Fellowship (FT130101875). DDF was supported by an international PhD scholarship from the QIMR Berghofer MRI and a UQ International Scholarship from the University of Queensland. The funders had no role in study design, data collection and analysis, decision to publish, or preparation of the manuscript.

\section{Availability of data and materials}

The pig mite datasets analysed during the current study are available in the GigaScience repository and raw data in NCBI under BioProject accession: PRJEB1242 [13]. The house dust mite, human mite and dog mite datasets are available in public NCBI databases.

\section{Authors' contributions}

KF conceived the study. DDF generated the experimental data. MZ, EM and ATP contributed to the bioinformatics work. DDF, SR, DH and KF performed the analysis. DDF, DH and KF wrote the manuscript. All authors read and approved the final version of the manuscript.

\section{Ethics approval and consent to participate}

Ethical approval for the use of shed skin crusts from the bedding of consenting patients with recurrent crusted scabies was obtained from the Human Research Ethics Committee of the Northern Territory Department of Health and Community Services and the Menzies School of Health Research (approval no. 13/2027). Animal care and handling procedures used in this study followed the Animal Care and Protection Act, in compliance with the Australian code of practice for the care and use of animals for scientific purposes, outlined by the Australian National Health and Medical Research Council. The study was approved by the Animal Ethics Committee of the QIMR Berghofer Medical Research Institute (QIMRB-P352). 


\section{Competing interests}

The authors declare that they have no competing interests.

\section{Publisher's Note}

Springer Nature remains neutral with regard to jurisdictional claims in published maps and institutional affiliations.

\section{Author details}

'QIMR Berghofer Medical Research Institute, Infectious Diseases Program, 300 Herston Road, Herston, Brisbane, QLD 4006, Australia. ${ }^{2}$ School of Veterinary Sciences, University of Queensland, Gatton, QLD 4343, Australia. ${ }^{3}$ Department of Veterinary Pathobiology, Faculty of Veterinary Medicine and Animal Science, University of Peradeniya, Peradeniya, Sri Lanka. ${ }^{4}$ Bioinformatics Division, Walter and Eliza Hall Institute of Medical Research, Parkville, Victoria 3052, Australia. ${ }^{5}$ Peter MacCallum Cancer Centre, Victorian Comprehensive Cancer Centre, Melbourne 3000, Australia. 'Department of Medical Biology, University of Melbourne, Parkville, Victoria 3010, Australia. ${ }^{7}$ Menzies School of Health Research, Charles Darwin University, Casuarina, Northern Territory, Australia.

Received: 15 December 2017 Accepted: 23 April 2018

Published online: 16 May 2018

\section{References}

1. Bornstein S, Mörner T, Samuel WM. Sarcoptes scabiei and sarcoptic mange. In: Margo S, Pybus J, Kocan AA, editors. Parasitic Diseases of Wild Mammals. Ames: lowa State University Press; 2008. p. 107-19.

2. Karimkhani C, Colombara DV, Drucker AM, Norton SA, Hay R, Engelman D, et al. The global burden of scabies: a cross-sectional analysis from the Global Burden of Disease Study 2015. Lancet Infect Dis. 2017;17:1247-54

3. Andrews RM, McCarthy J, Carapetis JR, Currie BJ. Skin disorders, including pyoderma, scabies, and tinea infections. Pediatr Clin North Am. 2009;56:1421-40.

4. Chosidow O. Scabies. N Engl J Med. 2006:354:1718-27.

5. Fuller LC. Epidemiology of scabies. Curr Opin Infect Dis. 2013;26:123-6.

6. Engelman D, Kiang K, Chosidow O, McCarthy J, Fuller C, Lammie P. Toward the global control of human scabies: introducing the International Alliance for the Control of Scabies. PLoS Negl Trop Dis. 2013;7:e2167.

7. Liu X, Walton S, Mounsey K. Vaccine against scabies: necessity and possibility. Parasitology. 2014;141:725-32.

8. Strong M, Johnstone P. Interventions for treating scabies. Cochrane Database Syst Rev. 2007;3:Cd000320.

9. Bernigaud C, Fang F, Fischer K, Lespine A, Aho LS, Dreau D, et al. Preclinical study of single-dose moxidectin, a new oral treatment for scabies: efficacy, safety, and pharmacokinetics compared to two-dose ivermectin in a porcine model. PLoS Negl Trop Dis. 2016;10:e0005030.

10. Currie BJ, Harumal P, McKinnon M, Walton SF. First documentation of in vivo and in vitro ivermectin resistance in Sarcoptes scabiei. Clin Infect Dis. 2004:39:e8-12.

11. Mounsey KE, Holt DC, McCarthy J, Currie BJ, Walton SF. Scabies: molecular perspectives and therapeutic implications in the face of emerging drug resistance. Future Microbiol. 2008;3:57-66

12. Fischer K, Holt DC, Harumal P, Currie BJ, Walton SF, Kemp DJ. Generation and characterization of cDNA clones from Sarcoptes scabiei var. hominis for an expressed sequence tag library: identification of homologues of house dust mite allergens. Am J Trop Med Hyg. 2003;68:61-4.

13. Mofiz E, Holt DC, Seemann T, Currie BJ, Fischer K, Papenfuss AT. Genomic resources and draft assemblies of the human and porcine varieties of scabies mites, Sarcoptes scabiei var. hominis and var. suis. Gigascience. 2016:5:23.

14. Rider SD, Morgan MS, Arlian LG. Draft genome of the scabies mite. Parasit Vectors. 2015;8:585.

15. Morgan MS, Arlian LG, Rider SD Jr, Grunwald WC Jr, Cool DR. A proteomic analysis of Sarcoptes scabiei (Acari: Sarcoptidae). J Med Entomol. 2016:53:553-61.

16. Arlian LG, Morgan MS, Rider SD. Sarcoptes scabiei: genomics to proteomics to biology. Parasit Vectors. 2016:9:380.

17. Fernando DD, Marr EJ, Zakrzewski M, Reynolds SL, Burgess STG, Fischer K. Gene silencing by RNA interference in Sarcoptes scabiei: a molecular tool to identify novel therapeutic targets. Parasit Vectors. 2017;10:289.
18. McKerrow JH, Caffrey C, Kelly B, Loke P, Sajid M. Proteases in parasitic diseases. Annu Rev Pathol. 2006;1:497-536.

19. O'Brien TC, Mackey ZB, Fetter RD, Choe Y, O'Donoghue AJ, Zhou M, et al. A parasite cysteine protease is key to host protein degradation and iron acquisition. J Biol Chem. 2008;283:28934-43.

20. Law RH, Smooker PM, Irving JA, Piedrafita D, Ponting R, Kennedy NJ, et al. Cloning and expression of the major secreted cathepsin B-like protein from juvenile Fasciola hepatica and analysis of immunogenicity following liver fluke infection. Infect Immun. 2003;71:6921-32.

21. Barrett AJ. Bioinformatics of proteases in the MEROPS database. Curr Opin Drug Discov Devel. 2004;7:334-41.

22. Bhargava A, Cotton JA, Dixon BR, Gedamu L, Yates RM, Buret AG. Giardia duodenalis surface cysteine proteases induce cleavage of the intestinal epithelial cytoskeletal protein villin via myosin light chain kinase. PLoS One. 2015:10:e0136102.

23. Olivos-Garcia A, Tello E, Nequiz-Avendano M, Gonzalez-Canto A, LopezVancell $\mathrm{R}$, Garcia de Leon $M C$, et al. Cysteine proteinase activity is required for survival of the parasite in experimental acute amoebic liver abscesses in hamsters. Parasitology. 2004;129:19-25.

24. Sajid M, McKerrow JH. Cysteine proteases of parasitic organisms. Mol Biochem Parasitol. 2002;120:1-21.

25. Blackman MJ. Proteases involved in erythrocyte invasion by the malaria parasite: function and potential as chemotherapeutic targets. Curr Drug Targets. 2000;1:59-83.

26. Ikeda T. Involvement of cysteine proteinases in excystment of Paragonimus ohirai metacercariae induced by sodium cholate and A23187. J Helminthol. 2003;77:21-6.

27. Maule AG. Parasitic flatworms: molecular biology, biochemistry, immunology and physiology In: Maule AG, Marks N, editors. Parasitic Flatworms: Molecular Biology, Biochemistry, Immunology and Physiology. Wallingford: CABI Publishing; 2006. p. 448

28. Donnelly S, Dalton J, Robinson M. How pathogen-derived cysteine proteases modulate host immune responses. Adv Exp Med Biol. 2011;712: 192-207.

29. Lecaille F, Kaleta J, Brömme D. Human and parasitic papain-like cysteine proteases: their role in physiology and pathology and recent developments in inhibitor design. Chem Rev. 2002;102:4459-88.

30. Nisbet AJ, Billingsley PF. Immunological control of scab mites: digestive enzymes as candidate compounds. Vet Parasitol. 1999;83:231-9.

31. Willadsen P. Vaccination against ectoparasites. Parasitology. 2006; 133(Suppl.):S9-25.

32. Selzer PM, Pingel S, Hsieh I, Ugele B, Chan VJ, Engel JC, et al. Cysteine protease inhibitors as chemotherapy: Lessons from a parasite target. Proc Natl Acad Sci USA. 1999:96:11015-22.

33. McKerrow JH. Development of cysteine protease inhibitors as chemotherapy for parasitic diseases: insights on safety, target validation, and mechanism of action. Int J Parasitol. 1999:29:833-7.

34. Levi A, Mumcuoglu KY, Ingber A, Enk CD. Assessment of Sarcoptes scabiei viability in vivo by reflectance confocal microscopy. Lasers Med Sci. 2011;26:291-2.

35. Holt DC, Burgess ST, Reynolds SL, Mahmood W, Fischer K. Intestinal proteases of free-living and parasitic astigmatid mites. Cell Tissue Res. 2013:351:339-52.

36. Holt DC, Fischer K. Novel insights into an old disease: recent developments in scabies mite biology. Curr Opin Infect Dis. 2013:26:110-5.

37. Fischer K, Holt D, Currie B, Kemp D. Scabies: important clinical consequences explained by new molecular studies. Adv Parasitol. 2012;79:339-73.

38. Beckham SA, Boyd SE, Reynolds S, Willis C, Johnstone M, Mika A, et al. Characterization of a serine protease homologous to house dust mite group 3 allergens from the scabies mite Sarcoptes scabiei. J Biol Chem. 2009;284:34413-22

39. Holt DC, Fischer K, Allen GE, Wilson D, Wilson P, Slade $R$, et al. Mechanisms for a novel immune evasion strategy in the scabies mite Sarcoptes scabiei: a multigene family of inactivated serine proteases. J Invest Dermatol. 2003;121:1419-24.

40. Bergstrom FC, Reynolds S, Johnstone M, Pike RN, Buckle AM, Kemp DJ, et al. Scabies mite inactivated serine protease paralogs inhibit the human complement system. J Immunol. 2009;182:7809-17.

41. Fischer K, Langendorf CG, Irving JA, Reynolds S, Willis C, Beckham S, et al. Structural mechanisms of inactivation in scabies mite serine protease paralogues. J Mol Biol. 2009;390:635-45. 
42. Mika A, Reynolds SL, Mohlin FC, Willis C, Swe PM, Pickering DA, et al. Novel scabies mite serpins inhibit the three pathways of the human complement system. PLoS One. 2012;7:e40489.

43. Holt DC, Fischer K, Pizzutto SJ, Currie BJ, Walton SF, Kemp DJ. A multigene family of inactivated cysteine proteases in Sarcoptes scabiei. J Invest Dermatol. 2004;123:240-1.

44. Shakib F, Gough L. The proteolytic activity of Der $p 1$ selectively enhances IgE synthesis: a link between allergenicity and cysteine protease activity. Clin Exp Allergy. 2000;30:751-2.

45. Lee AJ, Machell J, Van Den Broek AH, Nisbet AJ, Miller HR, Isaac RE, et al. Identification of an antigen from the sheep scab mite, Psoroptes ovis, homologous with house dust mite group I allergens. Parasite Immunol. 2002;24:413-22.

46. Chapman MD, Wunschmann S, Pomes A. Proteases as Th2 adjuvants. Curr Allergy Asthma Rep. 2007;7:363-7.

47. Todd AE, Orengo CA, Thornton JM. Sequence and structural differences between enzyme and nonenzyme homologs. Structure. 2002;10:1435-51.

48. Reynolds S, Fischer K. Pseudoproteases: mechanisms and function. Biochem J. 2015:468:17-24.

49. Sievers F, Wilm A, Dineen D, Gibson TJ, Karplus K, Li W, et al. Fast, scalable generation of high-quality protein multiple sequence alignments using Clustal Omega. Mol Syst Biol. 2011;7:539.

50. Nielsen H. Predicting secretory proteins with SignalP. Methods Mol Biol. 2017; 1611:59-73.

51. Schultz J, Milpetz F, Bork P, Ponting CP. SMART, a simple modular architecture research tool: Identification of signaling domains. Proc Natl Acad Sci USA. 1998;95:5857-64.

52. Gupta $R$, Jensen $L$, Brunak S. Orphan protein function and its relation to glycosylation. Ernst Schering Res Found Workshop. 2002;38:276-94.

53. Ferre F, Clote P. DiANNA: a web server for disulfide connectivity prediction. Nucleic Acids Res. 2005;33:230-2.

54. Combet C, Blanchet C, Geourjon C, Deleage G. NPS@: network protein sequence analysis. Trends Biochem Sci. 2000;25:147-50.

55. Rice P, Longden I, Bleasby A. EMBOSS: the European Molecular Biology Open Software Suite. Trends Genet. 2000;16:276-7.

56. Katoh K, Standley DM. MAFFT multiple sequence alignment software version 7: improvements in performance and usability. Mol Biol Evol. 2013;30:772-80.

57. Capella-Gutierrez S, Silla-Martinez JM, Gabaldon T. trimAl: a tool for automated alignment trimming in large-scale phylogenetic analyses. Bioinformatics. 2009;25:1972-3.

58. Darriba D, Taboada GL, Doallo R, Posada D. ProtTest 3: fast selection of bestfit models of protein evolution. Bioinformatics. 2011;27:1164-5.

59. Ronquist F, Huelsenbeck JP. MrBayes 3. Bayesian phylogenetic inference under mixed models. Bioinformatics. 2003;19:1572-4.

60. Stamatakis A. RAxML version 8: a tool for phylogenetic analysis and postanalysis of large phylogenies. Bioinformatics. 2014;30:1312-3.

61. Rapp CM, Morgan MS, Arlian LG. Presence of host immunoglobulin in the gut of Sarcoptes scabiei (Acari: Sarcoptidae). J Med Entomol. 2006;43:539-42.

62. Willis C, Fischer K, Walton SF, Currie BJ, Kemp DJ. Scabies mite inactivated serine protease paralogues are present both internally in the mite gut and externally in feces. Am J Trop Med Hyg. 2006;75:683-7.

63. Arlian LG. Biology, host relations, and epidemiology of Sarcoptes scabiei. Annu Rev Entomol. 1989;34:139-61.

64. Chan TF, Ji KM, Yim AK, Liu XY, Zhou JW, Li RQ. The draft genome, transcriptome, and microbiome of Dermatophagoides farinae reveal a broad spectrum of dust mite allergens. J Allergy Clin Immunol. 2015;135:539-48.

65. Reese ML, Zeiner GM, Saeij JP, Boothroyd JC, Boyle JP. Polymorphic family of injected pseudokinases is paramount in Toxoplasma virulence. Proc Natl Acad Sci USA. 2011;108:9625-30.

66. Proto WR, Castanys-Munoz E, Black A, Tetley L, Moss CX, Juliano L, et al. Trypanosoma brucei metacaspase 4 is a pseudopeptidase and a virulence factor. J Biol Chem. 2011;286:39914-25.

67. Santamaría ME, Hernández-Crespo P, Ortego F, Grbic V, Grbic M, Diaz I, et al. Cysteine peptidases and their inhibitors in Tetranychus urticae: a comparative genomic approach. BMC Genomics. 2012;13:307.

68. Thomas B, Heap P, Carswell F. Ultrastructural localization of the allergen Der $\mathrm{p} I$ in the gut of the house dust mite Dermatophagoides pteronyssinus. Int Arch Allergy Immunol. 1991;94:365-7.

69. Nisbet AJ, MacKellar A, McLean K, Brennan GP, Huntley JF. Eukaryotic expression of recombinant Pso o 1, an allergen from Psoroptes ovis, and its localization in the mite. Parasitology. 2007;134:83-9.
70. Tovey ER, Chapman MD, Platts-Mills TA. Mite faeces are a major source of house dust allergens. Nature. 1981;289:592-3.

71. Barros VC, Assumpção JG, Cadete AM, Santos VC, Cavalcante RR, Araújo RN, et al. The role of salivary and intestinal complement system inhibitors in the midgut protection of triatomines and mosquitoes. PLoS One. 2009;4:e6047.

72. Mika A, Reynolds SL, Pickering D, McMillan D, Sriprakash KS, Kemp DJ, et al. Complement inhibitors from scabies mites promote streptococcal growth - a novel mechanism in infected epidermis? PLoS Negl Trop Dis. 2012;6:e1563.

73. Reynolds SL, Pike RN, Mika A, Blom AM, Hofmann A, Wijeyewickrema LC, et al. Scabies mite inactive serine proteases are potent inhibitors of the human complement lectin pathway. PLoS Negl Trop Dis. 2014;8:e2872.

74. Swe PM, Reynolds SL, Fischer K. Parasitic scabies mites and associated bacteria joining forces against host complement defense. Parasite Immunol. 2014:36:585-93.

75. Swe PM, Christian LD, Lu HC, Sriprakash KS, Fischer K. Complement inhibition by Sarcoptes scabiei protects Streptococcus pyogenes - an in vitro study to unravel the molecular mechanisms behind the poorly understood predilection of S. pyogenes to infect mite-induced skin lesions. PLoS Negl Trop Dis. 2017;11:e0005437.

\section{Ready to submit your research? Choose BMC and benefit from:}

- fast, convenient online submission

- thorough peer review by experienced researchers in your field

- rapid publication on acceptance

- support for research data, including large and complex data types

- gold Open Access which fosters wider collaboration and increased citations

- maximum visibility for your research: over $100 \mathrm{M}$ website views per year

At BMC, research is always in progress.

Learn more biomedcentral.com/submissions 